\title{
Forecasting the demand for electric cars in Morocco
}

\author{
Aziza Chachdi ${ }^{* a b}$, Bouchra Rahmouni ${ }^{\mathrm{a}}$, Jamal Zahi $^{\mathrm{a}}$, Badr Ikken $^{\mathrm{b}}$ \\ ${ }^{a}$ Faculty of Juridical, Economic and Social Sciences, Km 3 route de Casablanca, B.P784, Settat, Morocco \\ ${ }^{b}$ Research Institute for Solar Energy and New Energies IRESEN, 16 Amir Sidi Mohamed Street Souissi, Rabat, Morocco
}

\begin{abstract}
In the face of the transition from existing transportation methods to electric vehicles, new economic models are indispensable in order to understand and anticipate the effect of this new sector on the automotive market. This document aims to develop three points related to the prediction of demand for electric vehicles in Morocco as a new technology not yet widespread in the country: conducting the survey, estimating the model, and forecasting. The structure of the model includes several significant variables. In order to study the determinants of future purchase of an electric car (EC), a multivariate logistic regression analysis was carried out by considering as a dependent variable the probability of purchase and as explanatory variables the respondent's socio-demographic characteristics, daily travel mode, and perception of ECs. The choice of the multiple logistic regression method was based on the fact that the dependent variable is a qualitative binomial with two modalities, yes or no. The results show that demand depends significantly on the age of the potential buyers of EC, their daily mileage travelled, as well as the owners of the classic cars that will be the most demanded of this type of vehicle. The findings will also be of interest to decision makers who wish to develop effective measures to stimulate this new sector.
\end{abstract}

Keywords: Electric car, multiple logistic regressions, forecast analysis

\section{Introduction}

One of the biggest environmental challenges of today is that of mobility and transportation. An almost endless network of vehicles and transportation systems is needed to support society and economies. Cars, buses, trains, trucks, and other modes of transport each leave a lasting impact on the environment.

Today, among the many solutions developed to promote the use of energy-efficient and clean modes of transport, electric vehicles can offer interesting alternatives. Indeed, in this environmental context favorable to renewable energies, electric vehicles represent environmental, climatic, technological, and societal stakes and have a role to play [1]. On the economic front, the emergence of this new form of mobility aims at economic development around a new industrial sector that includes the production of rechargeable batteries, electric vehicles, and hybrids; the installation of charging infrastructures in the private and public domains; the recycling of vehicles and batteries and the question of the second life of the latter. However, some points still need to be improved upon, such as the low battery life of the vehicles, lack of charging stations, lack of standards, and regulatory framework [2].

Driven by its commitment to implementing energy reforms and major orientations necessary for the protection of the environment and sustainable development, Morocco is launching strategies in several areas that support the achievement of its objectives. However, despite some progress, the introduction of electric vehicles in Morocco is only in its launch phase and documentation of its implementation and development is still poor. We found it useful to provide contributions related to the prediction of demand for electric cars (ECs) in Morocco as a new technology not yet widespread in the country through a cross-

\footnotetext{
* Manuscript received July 4, 2018; revised January 23, 2019.

Corresponding author. Tel.: +212-653-171-185; E-mail address:azizachachdi1 @ gmail.com.

doi: $10.12720 /$ sgce.8.2.191-200
} 
sectional survey, a design of an econometric model that is subject to purchase forecasts. The greatest attention has been devoted to the development and interpretation of the model.

The paper is structured as follows. The second section is devoted to the methodology followed. A literature review is made in order to identify the existing shortcomings in previous works on electric vehicles. The fourth section includes a description of the survey and data collection. The fifth section presents the assembly, estimation, and validation of the model. We conclude with the main results and discussion.

\section{Methodology}

First, a descriptive analysis was carried out on the population's sociodemographic characteristics, their daily mode of transport, and their attitudes toward ECs. Then we did a bivariate analysis to look for possible relationships between the explanatory variable (possibility of buying an EC) and the variables to explain using the classic statistical tests i.e., the Chi-squared test and Cramer's V according to the application conditions.

Finally, a multivariate analysis was carried out, where the dependent variable is the probability of purchase. The explanatory variables are the ones we have kept from bivariate analysis, for a critical threshold of less than $10 \%$. These significant variables were introduced into a logistic regression model by controlling the confusing factors and/or potential modifying effects. We proceeded by the descending method of progressive elimination of the explanatory variables in order to obtain the final model. The final model was subsequently validated through appropriate tests such as the adequacy and calibration test, correlation test, and homoscedasticity test.

\section{Literature Review}

Issues related to consumer behavior toward purchasing EC are rarely presented in the literature. Most of the studies focus mainly on the improvement of battery performance, the optimization of recharge time, or autonomy [3]. Countless researches have also been conducted on the problems resulting from the integration of these new technologies (VE) into the automotive market [4]. Others look to the modeling of the impact of factors related to the environment in the decision to purchase an electric vehicle [5].

Geographically, we find that there is a concentration of scientific research on clean vehicles in countries where electric vehicle use is highly developed, such as the United States [6]. For the French context, a microanalysis of electric vehicles and thermal vehicles available on the market was carried out in order to estimate their consumption costs. The main conclusion is that the cost of ECs is always higher than that of non-electric cars. This difference is likely to decrease if the volume of production increases [7]. In the Canadian context, the authors of the article "Assessing Consumer Preferences for Clean-fuel Vehicles: A Discrete Choice Experiment" tried to measure consumer preference for clean fuel cars versus conventional cars [8]. For these different reasons, we found it useful to evaluate the relationship between the demand for electric vehicles in Morocco at the national level and the influence factors, and how these factors influence it.

\section{Data Collection}

We use data from a cross-sectional survey conducted within the national territory and with statistical units that were selected by random sampling. The data collection was carried out via the Research Institute on Solar Energy and New Energies (IRESEN), based on the following two criteria:

- Inclusion criteria: Any person belonging to the target population, of Moroccan or foreign nationality, aged 18 and over, and present at the time of the survey.

- Exclusion Criteria: Anyone who was absent at the time of data collection, or who refused to participate in the study.

The questionnaire includes three main parts: the first is dedicated to the socio-demographic 
characteristics of the respondent, the second to the choice of the current travel mode, and the third to the preferences and different perspectives on ECs. The first distribution of the survey took place during COP22, where we could have a sample of respondents from varying nationalities and socio-professional backgrounds. More details on the survey, including the design of the questionnaire, method of sampling adopted, and analysis of the results are now available in the article "Socio-economic Analysis of Electric Vehicles in Morocco" [9].

Our sample of 425 observations is made up mainly of workers $(60.47 \%)$ who mostly travel to their offices by car $(67.70 \%)$ or by bus or taxi $(20.62 \%)$. The rest is divided between walking $(3.89 \%)$, motorcycle/bicycle (5.84\%), and other modes of transportation (1.95\%).

In order to get an idea of the results obtained, Table 1 below gives an overview of one of the most relevant questions of the survey: "Are you considering buying an EC?"

Table 1. Distribution of answers to the question "Are you considering buying an EC?" by gender:

\begin{tabular}{lrrr}
\hline Gender & Men & Women & Total \\
\hline No & 31 & 40 & 71 \\
Yes & 182 & 172 & 354 \\
Total & 213 & 212 & 425 \\
\hline
\end{tabular}

We observe that 354 respondents are considering buying an EC, of which 172 are women and 182 are men.

We recall that the greatest attention was given to the next section, namely, modeling. The answers to the various questions in the survey will serve as perceptual indicator variables, which will later be used for the construction of the econometric model.

\section{Model Specification}

\subsection{Determination of the variable of interest and defining co-variables}

We are interested in analyzing the possibility of future purchase of an EC. The variable to be predicted is as follows:

$$
\text { Purchase = } 1 \text { if "Yes"; Purchase }=0 \text { if "No" }
$$

Several elements have been analyzed, among others, the socio-economic dimension (age, gender, level of study, nationality, and profession), the daily mode of transport, and the respondent's view of ECs in Morocco. The predictive questions defined as variables are listed in Table 2 below:

Table 2. The co-variables of the model

\begin{tabular}{ll}
\hline Variable Name & Variable Description/Question \\
\hline IDI & Individual Identifier \\
Gender & Gender \\
Age & Age \\
Marital_status & Marital status \\
level_study & Level of education \\
profession & Profession \\
Nationality & Nationality \\
Location & Do you live in the same city as your workplace/school? \\
car_possession & Do you own a car? \\
means_trans & What is your preferred means of transportation? \\
mileage_traveled & How many kilometers do you travel daily? \\
time_spent & How much time do you spend on transportation? \\
reason_traveling & What is the main reason for choosing your means of transportation? \\
satisfaction & Are you satisfied with these modes of transportation? \\
EC_knowledge & Are you familiar with electric cars? \\
EC_purchase_price & What is your opinion of electric cars compared to the purchase price?
\end{tabular}




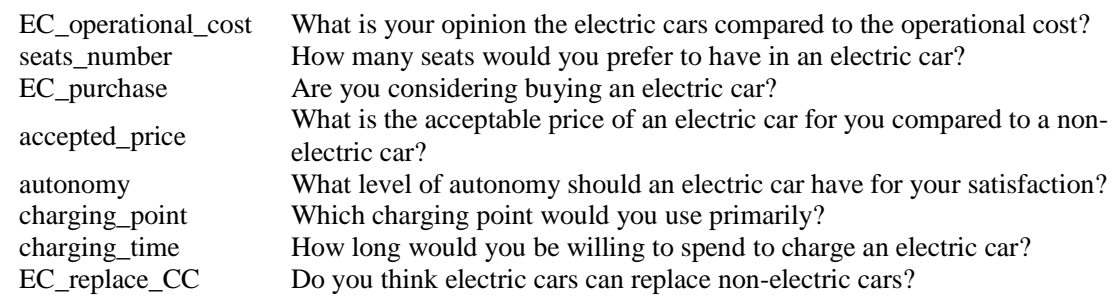

\subsection{Mounting the model}

The data from the survey was entered on CSV 2013 and analyzed using the software Stata version 13. To study the determinants of future purchase of an EC, a multivariate logistic regression analysis was carried out considering the probability of purchase as a dependent variable of our model, with the different predictors mentioned above as explanatory variables.

The choice of multiple logistic regression was because the variable of interest is a qualitative binomial with two modalities, yes/no. A theoretical reminder and an explicit formulation of the model are necessary [10][11].

\section{a. Explicit formulation of our model}

$\log \left(\frac{\text { probability }(\text { purchase }=\text { yes })}{1-\text { probability }(\text { purchase }=\text { yes })}\right)=\beta_{0}+\beta_{1} x_{1}+\beta_{2} x_{2}+\ldots .+\beta_{n} x_{n_{+} \varepsilon}$

$\beta_{\mathrm{i}}$ is the parameter to be estimated, related to the explanatory variables $\mathrm{x}_{\mathrm{i}}$ of the model (equation 1).

The choice of explanatory variables $x_{i}$ most relevant to study is based on the knowledge of the Moroccan consumer and the possible influential factors. Thus, not all the explanatory variables studied will necessarily be included in the multivariate analysis. They will only be introduced into the logistic regression variables that could be related to the variable $y$.

\section{b. Study of the correlation between the explanatory variables and the variable of interest:}

This step therefore consists of analyzing the correlation between the variable of interest and each variable xi by using the Chi-Square Test and Cramer's Test.

It should be noted that the primary objective of this part is to test the type of relationship between the variables taken in pairs. We naturally formulate two hypotheses:

- Null hypothesis noted by $\mathrm{H}_{0}$ : The two variables studied are independent.

- Alternative hypothesis noted by $\mathrm{H}_{1}$ : The two variables studied are not independent.

The rule is based on the p-value: if $\alpha_{\mathrm{obs}} \leq \alpha=1 \%$ or $5 \%$ or $10 \%$ or $20 \%$, we reject $\mathrm{H}_{0}$ at the risk of error $\alpha$. The explanatory variables that are sufficiently strong related to the variable to be explained are then retained in the initial model of the multiple logistic regression.

\subsection{Estimation and choice of the model:}

\section{a. Model estimation}

To estimate the logistic model i.e., to determine the real values of the parameters associated with the explanatory variables, we generally use the Maximum Likelihood Estimation (MLE) since it provides estimators with good statistical properties: without bias and low variance. Using Stata, a model without interaction is developed. This step consists of verifying the significance of the variables. After the check, we restart the regression while deleting the non-significant variables. Table 3 includes the results of the new regression: 
Table 3. Model estimation (without interaction)

\begin{tabular}{|c|c|c|}
\hline Variables & Modalities & Coefficients \\
\hline \multirow[t]{7}{*}{ age } & 18 - 25 years & REF \\
\hline & 26-35 years & -0.28 \\
\hline & & $(0.449)$ \\
\hline & $36-50$ years & 0.47 \\
\hline & & $(0.520)$ \\
\hline & Over 50 years & -0.80 \\
\hline & & $(0.482)$ \\
\hline \multirow[t]{3}{*}{ car_possession } & No & REF \\
\hline & Yes & 0.71 \\
\hline & & $(0.317)$ \\
\hline \multirow[t]{5}{*}{ time_spent } & Less than $1 \mathrm{~h}$ & REF \\
\hline & $1 \mathrm{~h}$ to $2 \mathrm{~h}$ & -0.70 \\
\hline & & $(0.321)$ \\
\hline & More than $2 \mathrm{~h}$ & -0.25 \\
\hline & & $(0.491)$ \\
\hline \multirow[t]{8}{*}{ reason_traveling } & I don't have an alternative & REF \\
\hline & I minimize the duration of my & -0.54 \\
\hline & & $(0.358)$ \\
\hline & I avoid parking problems & -1.14 \\
\hline & & $(0.652)$ \\
\hline & I minimize the cost & -0.16 \\
\hline & & $(0.571)$ \\
\hline & $\begin{array}{l}\text { I'm looking for safety and } \\
\text { comfort }\end{array}$ & $\begin{array}{l}-1.06 \\
(0.388)\end{array}$ \\
\hline \multirow[t]{3}{*}{ EC_operational_cost } & High & REF \\
\hline & Not high & -0.96 \\
\hline & & $(0.361)$ \\
\hline \multirow[t]{5}{*}{ EC_replace_CC } & No, I don't think so & REF \\
\hline & Yes, totally & -0.61 \\
\hline & & $(0.348)$ \\
\hline & Yes, partially & -1.50 \\
\hline & & $(0.465)$ \\
\hline _cons & & $\begin{array}{l}3.36 \\
(0.556)\end{array}$ \\
\hline
\end{tabular}

Several interactions have been made to improve the model obtained. We retain on Table 4 the gender variable that was introduced in interaction with age groups. So, the model will be:

Table 4. Model estimation (With interaction)

\begin{tabular}{lll}
\hline Variables & Modalities & Coefficients \\
\hline age & $\mathbf{1 8}$ - 25 years & REF \\
& 26-35 years & 0.52 \\
& & $(0.608)$ \\
& 36-50 years & 0.72 \\
& & $(0.632)$ \\
& Over 50 years & -0.47 \\
car_possession & No & $(0.617)$ \\
& Yes & REF \\
Gender & Men & $0.74^{* *}$ \\
& Women & $(0.321)$ \\
& & REF \\
Gender\#age & Women\#18-25 years & 0.88 \\
& Women\#26-35 years & $(0.774)$ \\
& & REF \\
& & $-1.67 * *$ \\
& & $(0.913)$
\end{tabular}




\begin{tabular}{|c|c|c|}
\hline & Women\#\#36-50 years & -0.73 \\
\hline & Women\#\#over than 50 years & $\begin{array}{l}(1.072) \\
-0.91 \\
(0.952)\end{array}$ \\
\hline \multirow[t]{3}{*}{ time_spent } & Less than $1 \mathrm{~h}$ & REF \\
\hline & $1 \mathrm{~h}$ to $2 \mathrm{~h}$ & $\begin{array}{l}-0.73 * * \\
(0.326)\end{array}$ \\
\hline & More than $2 \mathrm{~h}$ & $\begin{array}{l}-0.35 \\
(0.487)\end{array}$ \\
\hline \multirow[t]{5}{*}{ reason_traveling } & I don't have an alternative & REF \\
\hline & I minimize the duration of my trip & $\begin{array}{l}-0.56^{*} \\
(0.360)\end{array}$ \\
\hline & I avoid parking problems & $-1.04 *$ \\
\hline & I minimize the cost & $\begin{array}{l}(0.658) \\
-0.00 \\
(0.591)\end{array}$ \\
\hline & I'm looking for safety and comfort & $\begin{array}{l}-1.06^{* * *} \\
(0.393)\end{array}$ \\
\hline \multirow[t]{2}{*}{ EC_operational_cost } & High & REF \\
\hline & Not high & $\begin{array}{l}-0.93 * * * \\
(0.378)\end{array}$ \\
\hline \multirow[t]{3}{*}{ EC_replace_CC } & No, I don't think so & REF \\
\hline & Yes, totally & $\begin{array}{l}-0.59^{*} \\
(0.354)\end{array}$ \\
\hline & Yes, partially & $-1.51 * * *$ \\
\hline _cons & & $\begin{array}{l}(0.477) \\
3.00 * * * \\
(0.580)\end{array}$ \\
\hline
\end{tabular}

Note:

REF means reference and comparison modality between the modalities of the same variable.

The brackets indicate the standard errors.

* indicates that the coefficient is significant at the critical threshold of $10 \%$.

** indicates that the coefficient is significant at the critical threshold of $5 \%$.

***Indicates that the coefficient is significant at the critical threshold of $1 \%$.

\section{b. Model selection}

The likelihood ratio test is often used to compare models two to two. On the other hand, when many models have to be compared between them, the risk of rejecting the null hypothesis when it is true increases substantially. To address this problem, a possible solution is to compare models using the Akaike information criterion (AIC) and Bayesian information criterion (BIC) as shown in Table 5. The best model is that which possesses the lowest AIC and/or BIC:

Table 5. AIC and BIC of the models

\begin{tabular}{lll}
\hline & AIC & BIC \\
\hline Model without interaction & 358.2102 & 414.9395 \\
Model with interaction & 361.8369 & 434.745
\end{tabular}

On the other hand, the estimated coefficients as presented on the logit model are not interpretable (Tables 3 and 4). We then calculate on Table 6 the marginal effects called ODDS ratios for the final model adopted: 
Table 6. Final model

\begin{tabular}{|c|c|c|c|}
\hline Variables & Modalities & Coefficients & Odds Ratio \\
\hline \multirow[t]{7}{*}{ age } & 18 - 25 years & REF & REF \\
\hline & $26-35$ years & -0.28 & 0.75 \\
\hline & & $(0.449)$ & $(0.306)$ \\
\hline & $36-50$ years & 0.47 & 1.60 \\
\hline & & $(0.520)$ & $(0.781)$ \\
\hline & Over 50 years & $-0.80^{*}$ & $0.44 *$ \\
\hline & & $(0.482)$ & $(0.206)$ \\
\hline \multirow[t]{3}{*}{ car_possession } & No & REF & REF \\
\hline & Yes & $0.71 * *$ & $2.04 * *$ \\
\hline & & $(0.317)$ & $(0.635)$ \\
\hline \multirow[t]{5}{*}{ time_spent } & Less than $1 \mathrm{~h}$ & REF & REF \\
\hline & $1 \mathrm{~h}$ to $2 \mathrm{~h}$ & $-0.70 * *$ & $0.49 * *$ \\
\hline & & $(0.321)$ & $(0.156)$ \\
\hline & More than $2 \mathrm{~h}$ & -0.25 & 0.77 \\
\hline & & $(0.491)$ & $(0.370)$ \\
\hline \multirow[t]{9}{*}{ reason_traveling } & I don't have an alternative & REF & REF \\
\hline & I minimize the duration of my trip & $-0.54 *$ & $0.58^{*}$ \\
\hline & & $(0.358)$ & $(0.208)$ \\
\hline & I avoid parking problems & $-1.14^{*}$ & $0.31 *$ \\
\hline & & $(0.652)$ & $(0.249)$ \\
\hline & I minimize the cost & -0.16 & 0.85 \\
\hline & & $(0.571)$ & $(0.471)$ \\
\hline & I'm looking for safety and comfort & $-1.06 * * *$ & $0.34 * * *$ \\
\hline & & $(0.388)$ & $(0.137)$ \\
\hline \multirow[t]{3}{*}{ EC_operational_cost } & High & REF & REF \\
\hline & Not high & $-0.96 * * *$ & $0.38 * * *$ \\
\hline & & $(0.361)$ & $(0.137)$ \\
\hline \multirow[t]{5}{*}{ EC_replace_CC } & No, I don't think so & $\mathrm{REF}$ & REF \\
\hline & Yes, totally & $-0.61 * * *$ & $0.54 * * *$ \\
\hline & & $(0.348)$ & $(0.187)$ \\
\hline & Yes, partially & $-1.50 * * *$ & $0.22 * * *$ \\
\hline & & $(0.465)$ & $(.0994)$ \\
\hline \multirow[t]{2}{*}{ _cons } & & $3.36^{* * *}$ & $28.88 * * *$ \\
\hline & & $(0.556)$ & (14.797) \\
\hline
\end{tabular}

\subsection{Validation of the model}

Several tests have been adopted at this level, including the calibration test, autocorrelation test of errors, and homoscedasticity. The main purpose of this section is to answer two questions: Is the selected model good? Does it really represent the individuals surveyed?

\section{a. Model calibration Test: Hosmer \& Lemeshow Test}

The principle of the Hosmer and Lemeshow test consists of comparing the predicted and observed values of the modalities of the variable of interest, after grouping individuals into classes. We then use the Chi-square distance to calculate the distance between observed and predicted frequencies. When this distance is relatively small, we consider that the model is well-calibrated. The test is based on the following assumptions: $\mathrm{H}_{0}$ : the model is well-calibrated (model is correct) against $\mathrm{H}_{1}$ : the model is not well-calibrated (the model is incorrect).

Table 7 shows that from Stata 13, estatgof provides the Pearson and Hosmer-Lemeshow regression quality test: 
Table 7. Final model

\begin{tabular}{ll}
\hline \multicolumn{2}{c}{ Logistic model for purchase, goodness-of-fit test } \\
\hline Number of observations & 425 \\
Number of covariate patterns & 208 \\
Pearson chi ${ }^{2}(194)$ & 204.63 \\
Prob> chi &
\end{tabular}

The above table of results shows that the overall fit of the model to the data is satisfactory. This is because the value of the associated critical probability (Prob $>\mathrm{chi}^{2}$ ) is greater than the significance level of $5 \%$. In other words, at a risk level of 5\%, we cannot reject H0. So, the model is valid and compatible with the data collected.

\section{b. Residue analysis:}

In Fig. 1, the analysis of residues (estimation errors, unobservable and unmeasured hazards) shows that they are uncorrelated and inter-dispersed. In other words, the relationship between the two errors is zero $(\mathrm{COV}(\varepsilon \mathrm{i} ; \varepsilon \mathrm{i}-1)=0)$ :

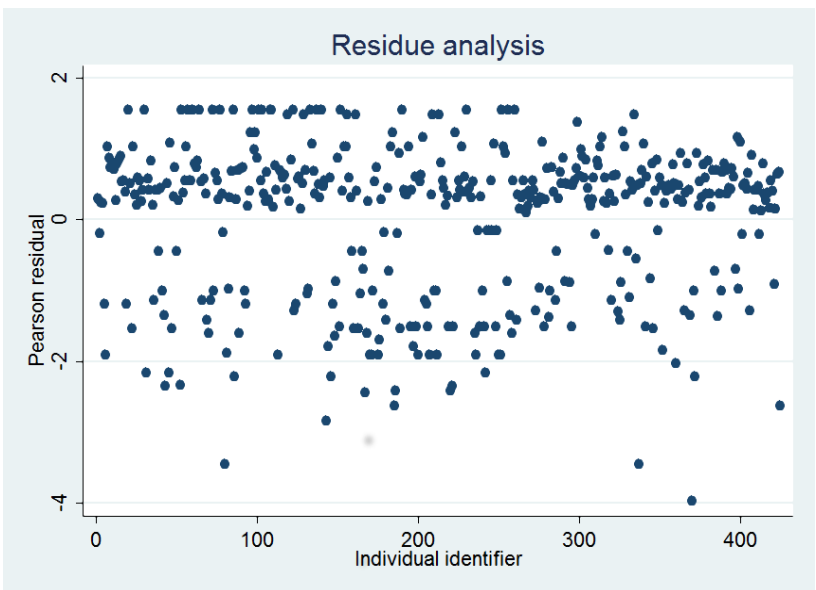

Fig.1. Residue analysis

\section{Result and Discussion}

After the first estimate, several variables were not significant at the $10 \%$ threshold, which led us to eliminate them from the model. We only retain those that are statistically significant while having a positive or negative impact on our variable of interest. Based on the AIC/BIC criteria, the model without interaction is the most adapted to our data.

Each respondent to the survey was asked about the main influencing factors in his/her decision of purchasing an EC and about his/her knowledge and perceptions of ECs. Questions also concerned transportation trends, household socio-economic background, education level, etc. When we think of the consumers most likely to adopt the electric trend in the automotive industry, we tend to think of millennials and members of Generation Y, which include buyers between 18 to 35 years old who are generally more open to new technologies. It would therefore be theoretically normal for this demographic to adopt the idea of an EC more easily than people of other age groups. However, it seems that this is not the case. Indeed, respondents to the early use of EC tended to be people between 36 and 50 years of age. There are a number of reasons that partly explain these results, for example, the lack of information and the high price of EC.

As for people with non-electric car, the probability of purchase is very high for this category and is statistically very significant (close to $2 \%$ ). This result states that EC has characteristics that approximate 
existing products in the automotive market, namely non-electric cars, while meeting the same needs of future EC applicants. It is therefore a favorable market for industrialists wishing to increase their market share in Morocco's automotive sector.

For the question "How much time do you spend on transportation?" it has a negative and significant influence on the probability of buying an EC, especially for people who spend between one hour and two hours on their daily commutes or journeys. EC demand is not available for this group of people for several reasons, such as the lack of availability of public charging stations on the Moroccan road network and the limited autonomy of the car.

As for the question "What is your opinion of the electric car compared to the operational cost?" the possibility of buying an EC decreases very sharply (almost 61.93\%) for people who feel that the operational cost is high. Contrary to the ideas received, an EC requires less frequent maintenance than a non-electric car, and the list of parts to be changed is considerably reduced (no belt, oil, spark plug, etc.), including the pads and brake discs which have a much longer lifespan. On the other hand, the tires of ECs tend to experience slightly more wear than their non-electric counterparts due to the start-up torque.

For the question "Do you think the EC will gradually replace the classic car?" the influence is negative and statistically very significant. That is to say, most of the people surveyed believe that ECs could gradually replace traditional non-electric cars, but a minority disagree.

\section{Conclusion}

The demand for ECs in Morocco is equally sensitive to such factors as the age of potential buyers, their daily mileage, as well as which owners of traditional non-electric cars will most demand this type of vehicle. These elements are then major triggers to promoting the development of strategies for the fluid entry of this type of vehicle in Morocco.

Knowledge of mobility trends and preferences as well as general opinions of ECs will give a clear picture to decision makers and stakeholders in the field of transportation across the country, in order to initiate vigorous efforts to deploy ECs.

On the infrastructure front, and as EC adoption rates continue to accelerate worldwide and exceed market penetration estimates of just a few years ago, it is important for local electricity networks to be ready for a fundamental shift in national personal transport.

At the governmental level, the local authorities have several strengths and capacities relevant to the deployment of ECs that are lacking in public services, including the ability to adopt regulations on the EC infrastructure, the possibility of encouraging the purchase and use of ECs, and the freedom to actively promote ECs and engage in related outreach efforts.

The logistic model without interaction adopted as part of this empirical research has produced better predictive performance data. The constant term is positive and very significant (the associated p-value is zero) at the critical threshold of $1 \%$. This means that there are other latent and unmeasured variables in our cross-sectional survey that further explain the future behavior of individuals in relation to the purchase of ECs. In this sense, it would be highly relevant to conduct additional simulations with other explanatory variables besides those defined in our survey.

\section{Acknowledgments}

This paper was financed by Gesellschaft für Internationale Zusammenarbeit (GIZ) and Research Institute for Solar Energy and New Energies (IRESEN).

\section{References}

[1] Angot L. La mobilité électrique dans les systèmes de transport et de mobilité urbains: constats et perspectives. Comment développer une nouvelle offre de mobilité durable par le biais de l'électromobilité dans la métropole toulousaine? Mémoire de Master. Aménagement et Projets de Territoires.France; 2014. 
[2] Wirasingha SG, Emadi A. Classification and review of control strategies for plug-in hybrid electric vehicles. Vehicular Technology IEEE Transactions, 2011; pp: 111-122.

[3] Brandl M, Gall H, Wenger M, Lorentz V, Giegerich M, Baronti F et al. Batteries and Battery Management Systems for Electric Vehicles. In: IEEE Design, Automation \& Test in Europe Conference \& Exhibition, 2012.

[4] Botero AF, Rios AM. Demand Forecasting Associated with Electric Vehicle Penetration on Distribution Systems. In: IEEE Eindhoven PowerTech, 2015.

[5] Alvarez-Daziano R, Bolduc D. Canadian consumers' perceptual and attitudinal responses toward green automobile technologies: an application of Hybrid Choice Models. European Summer School in Resources Environmental Economics: Economics, Transport and Environment, Venice International University; 2009.

[6] Bunch DS, Bradley M, Thomas FG, Kitamura R, Occhiuzzo G. Demand For Clean-Fuel Vehicles In California: A DiscreteChoice Stated Preference Pilot Project. Transportation Research Part A: Policy and Practice, 1993; 27A (3):237-253.

[7] Fontainhasa J, Cunha J, Ferreira P. Is investing in an electric car worthwhile from a consumers' perspective? Journal Energy, 2016; pp:1459-1477.

[8] Ewing G, Sarigollu E. Assessing Consumer Preferences for Clean-Fuel Vehicles: A Discrete Choice Experiment. Journal of Public Policy and Marketing, 2000; 19(1):106-118.

[9] Chachdi A, Rahmouni B, Aniba G. Socio-economic Analysis of Electric Vehicles in Morocco. Energy Procedia, 2017;pp: 644-653.

[10] Ricco Rakotomalala R. (May 2017). Pratique de la Régression Logistique, Régression Logistique Binaire et Polytomique. [Online]. Available: https://eric.univ-lyon2.fr/ ricco/cours/cours/pratique_regression_logistique.pdf

[11] El Sanharawia M, Naudetd F. Comprendre la régression logistique. Journal Français d'Ophtalmologie, 2013; pp: 710-715. 